\title{
Bonding Integrity of Hybrid 18Ni300-17-4 PH Steel Using The Laser Powder Bed Fusion Process For The Fabrication of Plastic Injection Mould Inserts
}

Yuk Lun Simon Chan ( $\nabla$ ycha723@aucklanduni.ac.nz )

University of Auckland https://orcid.org/0000-0003-4041-1544

Olaf Diegel

University of Auckland

Xun Xu

University of Auckland

\section{Research Article}

Keywords: Additive manufacturing, Hybrid-build, Laser powder bed fusion, Maraging 300 steel, 17-4 PH steel

Posted Date: December 1st, 2021

DOI: https://doi.org/10.21203/rs.3.rs-1097184/v1

License: (a) (1) This work is licensed under a Creative Commons Attribution 4.0 International License. Read Full License 


\title{
Bonding integrity of hybrid 18Ni300-17-4 PH steel using the
}

\author{
laser powder bed fusion process for the fabrication of plastic
}

\section{injection mould inserts}

\author{
Yuk Lun Simon Chan ${ }^{1,2^{*}}$, Olaf Diegel ${ }^{1,2}$ and Xun $\mathrm{Xu}^{2}$ \\ $1^{*}$ Creative Design and Additive Manufacturing Lab, The University of Auckland, \\ Auckland, New Zealand. \\ ${ }^{2}$ Department of Mechanical and Mechatronics Engineering, The University of Auckland, \\ Auckland, New Zealand. \\ *Corresponding author(s). E-mail(s): ycha723@aucklanduni.ac.nz; \\ Contributing authors: olaf.diegel@auckland.ac.nz; x.xu@auckland.ac.nz;
}

\begin{abstract}
Laser powder bed fusion (LPBF) is a metal additive manufacturing (AM) process for fabricating high-performance functional parts and tools in various metallic alloys, such as titanium, aluminium and tool steels. The process can produce geometrically complex features such as conformal cooling channels $(\mathrm{CCC})$ in plastic injection mould inserts to improve cooling efficiency. A recent attempt using a hybrid-build LPBF AM technique to fabricate aluminium mould inserts with CCC attained a substantial reduction in processing time, making it an attractive alternative method to the mouldmaking industry. Also, the successful bonding of aluminium powder with wrought aluminium alloys proved the practicability of this concept. This study further investigates whether a similarly successful outcome could apply to tool steel since tool steel is the preferred material for constructing highgrade high-volume plastic injection moulds. In this investigation, hybrid $18 \mathrm{Ni300}$ powder-wrought 17-4 PH steel parts were additively fabricated using the hybrid-build LPBF technique, followed by various post-build heat treatments. The mechanical and metallurgical properties of the samples' bonded interface were examined. Microstructure analysis revealed homogenous powder-substrate fusion across the interface region. Results from tensile tests confirmed strong powder-substrate bonding as none of the tensile fractures occurred at the interface. A direct post-build one-hour agehardening treatment achieved the best combination of hardness, tensile strength, and ductility. The overall result demonstrates that hybrid-built $18 \mathrm{Ni} 300-17-4 \mathrm{PH}$ steel can be a material choice for manufacturing durable and high-performance injection mould inserts for high-volume production.
\end{abstract}

Keywords: Additive manufacturing, Hybrid-build, Laser powder bed fusion, Maraging 300 steel, 17-4 PH steel 


\section{Introduction}

Laser powder bed fusion (LPBF) is a metal additive manufacturing (AM) process utilising high intensified laser energy to selectively fuse fine metal powder particles layer upon layer within regions of a powder bed [1]. With modern metal AM systems, the process can fabricate fully dense high-performance functional parts and tools of high complexity in various metallic alloys such as titanium, stainless steel, aluminium, and tool steels. One specific application is the fabrication of conformal cooling channels (CCC) for injection mould inserts to improve cooling efficiency [2-4]. Despite its functional benefit, this new technology is still not widely adopted in the mould-making industry as the processing speeds are slow and metal AM systems are expensive.

A recent attempt by Chan et al. [5] using a hybrid-build LPBF AM technique to fabricate aluminium mould inserts with CCC attained a substantial reduction in processing time, making it an attractive alternative method to the mouldmaking industry. Also, the successful bonding of aluminium powder with wrought aluminium alloys proved the practicability of this concept for industrial applications [6]. However, as tool steel is the preferred material type for constructing highvolume high-performance plastic injection moulds [7], further investigation is needed on whether a similarly successful outcome could apply to tool steels.

Various investigations have been carried out on the bonding of $18 \mathrm{Ni} 300$ maraging steel powder with various types of wrought substrate tool steels. Early work on fracture behaviour of hybrid-built $18 \mathrm{Ni300-H13}$ steel revealed that peak hardness/tensile strength could be achieved with a special age-hardening treatment targeting the H13 substrate [8]. However, tensile fracture occurred at the bonded interface. It was later suggested that the failure was caused by a combination of chemical and microstructural inhomogeneity, compounded by increased porosity at the $18 \mathrm{Ni} 300-\mathrm{H} 13$ interface [9]. Another study on fracture toughness of hybrid-built 18Ni300-H13 and $18 \mathrm{Ni300-420}$ tool steels also found a crack growth path along the interface boundary, indicating a brittle mechanics fracture resulting from build defects [10]. Therefore, even though H13 and 420 are widely used tool steels for manufacturing high-grade plastic injection moulds, their suitability as the substrate for combining powder $18 \mathrm{Ni} 300$ maraging steel in the hybrid-build approach, as demonstrated by the studies mentioned above, is questionable.

On the other hand, there is no study yet on another commonly used wrought tool steel, the precipitation-hardenable steels, such as 17-4 $\mathrm{PH}$ steel, about their suitability to bond with $18 \mathrm{Ni} 300$ maraging steel powder. If successful, this steel 
combination could be a material choice for manufacturing durable and high-performance injection mould inserts using the LPBF hybrid-build technique. Results from this line of inquiry will therefore have significant implications for industry practice.

\section{Background}

\subsection{Ni300 maraging steel}

Maraging steels are a unique class of low-carbon, high-nickel steels that acquire their strength from the precipitation of intermetallic alloy elements. They are renowned for their superior strength, high toughness, good machinability, good weldability and dimensional stability through age hardening. One particular grade, $18 \mathrm{Ni} 300$, is commonly used as tool steel for extrusion dies, plastic injection moulds, aluminium and zinc die casting moulds, and hot pressing dies [11]. Due to its popularity in industries, LPBF built $18 \mathrm{Ni300}$ maraging steel has been widely studied for its suitability in metal AM applications since the early 2010s.

Early investigation in the processing of this material by Yasa et al. revealed that, at a specific energy density threshold, near-fully dense parts with mechanical properties comparable to the wrought counterpart could be produced by applying laser re-melting after every layer [12]. However, this came at the cost of longer build time. They also found that while an increase in laser scanning speed and layer thickness affected the macrohardness due to higher porosity, their effect on the microhardness was insignificant. Equipped with more advanced LPBF systems, researchers recently carried out in-depth studies on other influential process parameters. One study reported that an XY scanning strategy could reduce the anisotropy and surface roughness of the AM built parts, resulting in high-quality products with homogeneous mechanical properties [13]. Another study found that processed with a thicker powder layer of $50 \mu \mathrm{m}$ could reduce energy consumption and production time with only a slight reduction in strength and ductility [14].

As mentioned earlier, the strength and hardness of wrought maraging steels can be enhanced via an age-hardening process. This heat treatment process allows the formation of a uniform distribution of fine nickel-rich intermetallic precipitates to strengthen the martensitic matrix [15]. Hence, it is imperative to examine and understand the behaviour of aged LPBF-built 18Ni300 steel parts. Among various age-hardening conditions, a combination of ageing temperature at $480{ }^{\circ} \mathrm{C}$ for 5 hours was found to give an ultra-high-strength of about $2200 \mathrm{MPa}$ and high hardness of about $650 \mathrm{HV}$ (58 HRC) [12]. However, when compared with the asbuilt condition, ductility dropped substantially by 
nearly $90 \%$ to $1.6 \%$ after ageing. A later investigation by Tan et al. [16] revealed that ductility could be increased to about $3.3 \%$ by heat-treating the parts at $490{ }^{\circ} \mathrm{C}$ for 6 hours. Moreover, a two-step solution annealing $\left(840{ }^{\circ} \mathrm{C} / 1 \mathrm{~h}\right)$ and age hardening $\left(490{ }^{\circ} \mathrm{C} / 6 \mathrm{~h}\right)$ technique could further increase the ductility to $5.6 \%$ with only a slight drop in ultimate tensile strength.

When considering using LPBF-built maraging steel as mould inert material, understanding its machinability with heat treatment is also essential as the AM fabricated part will require post-build machining to achieve the final dimensions and shape. A recent study by Bai et al. [17] revealed that as-built and solution-annealed maraging steel parts have better machinability than the agehardened ones. The cutting force and tool wear decreased by almost 50\% in comparison. Overall, a surface roughness $(\mathrm{Ra})$ of below $0.6 \mu \mathrm{m}$ after milling was attainable.

\subsection{7-4 PH steel}

17-4 PH steel is a grade of low-carbon, highchromium martensitic stainless steel. Due to its good corrosion resistance and excellent mechanical properties, 17-4 PH steel is widely used as structural materials for chemical and power plants, aerospace parts and mechanical engineering components [18]. Hence, it could be well-suited as the base structure/substrate for hybrid-building of injection mould inserts. Like $18 \mathrm{Ni300}$ maraging steel, 17-4 PH steel can be aged or precipitationhardened to achieve ultra-high strength and high hardness [19-21]. Hence, additively built parts with $18 \mathrm{Ni} 300$ powder-wrought $17-4 \mathrm{PH}$ steel can be post-processed using similar heat treatment procedures.

\subsection{Methodology}

This investigation is an ongoing research project on hybrid-built hybrid-metal by the authors. Hence, the same experimental methodology applied in the previous hybrid-aluminium study [6] was also employed here in this hybrid-steel study.

In this study, powder $18 \mathrm{Ni} 300$ steel was additively deposited onto pre-machined round wrought 17-4 PH blanks using the LPBF process. The mechanical and metallurgical properties of the bonded interface of as-built and heat-treated hybrid-built samples were investigated. Tensile tests were conducted to determine the rupture position and the strength of the hybrid-built specimens. Stand-alone LPBF-built $18 \mathrm{Ni300}$ and wrought 17-4 PH samples were also used as a baseline in the tensile test for comparison. Optical microscopy (OM), scanning electron microscopy (SEM), and energy-dispersive X-ray spectroscopy (EDS) techniques were employed to examine the 18Ni300-17-4 PH interface. Microhardness tests were also performed to identify the hardness change across the interface region. A possible 
application using this manufacturing technique was also proposed.

\section{Experimental procedure}

\subsection{Materials}

The materials chosen for this investigation were 18Ni300 maraging steel powder, supplied by EOS $\mathrm{GmbH}$ under the trade name MS1, and wrought 17-4 PH stainless steel, supplied in solutiontreated condition (condition A) by BGH Edelstahl Freital GmbH. Table 1 shows the chemical composition of both materials as stated in the test certificates. The gas-atomised MS1 steel powder particles, as stated in the certificate [22], were predominantly spherical with diameter ranges between 20-54 $\mu \mathrm{m}$ (Fig. 1). The wrought 17-4 PH steel was supplied as $19.05 \mathrm{~mm}$ round stock.

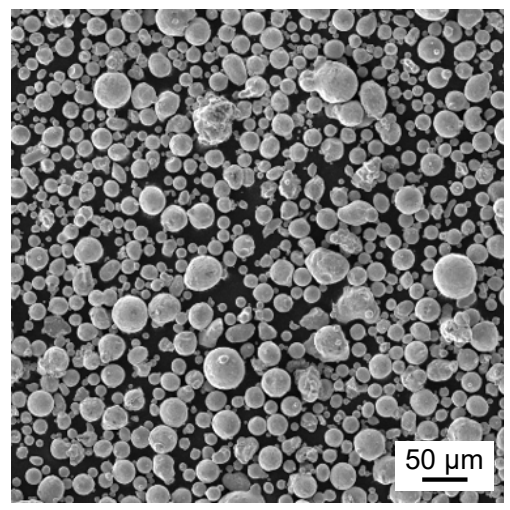

Fig. 1 SEM micrograph of MS1 powder (Excerpted from [22])

\subsection{Processing}

\subsubsection{Design of hybrid-build samples}

Two types of hybrid-build samples were designed for tensile tests (TT) and microstructure analysis (MA), as shown in Figure 2. All substrate blanks were prepared by turning from the $19 \mathrm{~mm}$ diameter stock bar. After the LPBF process, specimens for examination (shaded area in Fig. 2) were obtained by conventional CNC turning and milling.

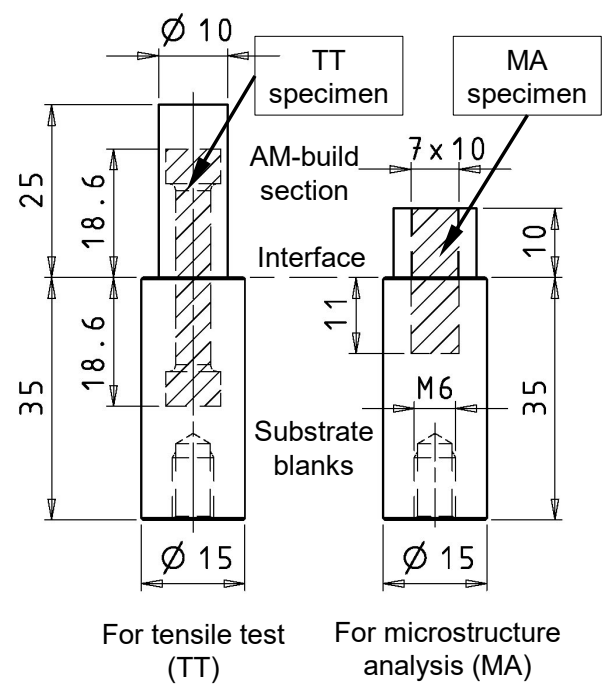

Fig. 2 Design of the hybrid-build samples

\subsubsection{Fabrication}

Eight hybrid-built samples, four for tensile test and four for microstructure analysis, were fabricated in one single build on an EOS M290 metal LPBF machine. All substrate blanks were mounted onto the build plate with M6 cap screws under $14 \mathrm{Nm}$ of tightening torque. In addition, 


\begin{tabular}{cccccccccccccccc}
\hline & $\mathrm{C}$ & $\mathrm{Si}$ & $\mathrm{Mn}$ & $\mathrm{P}$ & $\mathrm{S}$ & $\mathrm{Cr}$ & $\mathrm{Mo}$ & $\mathrm{Ni}$ & $\mathrm{Ti}$ & $\mathrm{Cu}$ & $\mathrm{Nb}$ & $\mathrm{Co}$ & $\mathrm{Al}$ & $\mathrm{Ta}$ & $\mathrm{Fe}$ \\
\hline $18 \mathrm{Ni} 300$ & 0.01 & 0.09 & 0.05 & 0.01 & 0.01 & 0.13 & 4.57 & 17.27 & 0.68 & 0.02 & na & 8.53 & 0.09 & na & Bal. \\
\hline $17-4 \mathrm{PH}$ & 0.05 & 0.37 & 0.63 & 0.02 & na & 15.6 & 0.13 & 4.22 & na & 3.21 & 0.25 & 0.03 & na & 0.01 & Bal. \\
\hline
\end{tabular}

four stand-alone $18 \mathrm{Ni} 300$ tensile samples, Ø10 x $45 \mathrm{~mm}$ in size, were fabricated vertically from a separate setup for baseline strength comparisons. In both builds, the build plate's temperature was set to $40{ }^{\circ} \mathrm{C}$, and the build chamber was made inert with nitrogen gas to maintain the oxygen concentration at $1.3 \%$. As recommended by EOS, optimised LPBF process parameters for MS1, as listed in Table 2, were used for the two builds. Additionally, the first three layers of powder were set to be scanned twice or re-melted by the laser to ensure defect-free bonding. Figure 3 shows the two types of fabricated hybrid 18Ni300-17-4 PH samples.

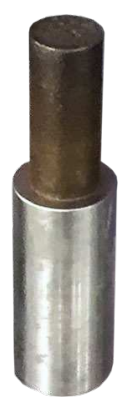

For tensile test
AM-built $18 \mathrm{Ni} 300$

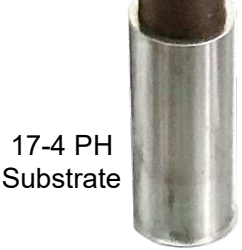

For microstructure analysis
Fig. 3 Fabricated 18Ni300-17-4 PH samples

\subsubsection{Post-build heat treatments}

Three different types of samples, as-built/assupplied, solution-annealed, and age-hardened in four groups, were examined in this study. Three samples from each group were heat-treated, one solution-annealed and two age-hardened. Before heat treatments, all samples were pre-machined, with minimum material stock left for final turning, milling and surface grinding (Fig. 4). The heat treatment conditions used were designated as:

- HT0 - as-built/as-supplied

- HT1 - solution annealing, $940{ }^{\circ} \mathrm{C} / 2 \mathrm{~h} /$ air cooling

- HT2 - age-hardening, $490{ }^{\circ} \mathrm{C} / 1 \mathrm{~h} /$ air cooling

- HT3 - age-hardening, $490{ }^{\circ} \mathrm{C} / 6 \mathrm{~h} /$ air cooling

Both HT1 and HT3 are conditions specified by EOS for MS1 maraging steel for industry practice, whereas HT2 was set in this study for evaluation. Table 3 lists all the set heat treatment conditions for this study. All heat treatments were carried out in a laboratory-type Thermo Fisher F30430 muffle furnace. All heat-treated samples were air-cooled outside the furnace. 
Table 2 LPBF optimised process parameters

\begin{tabular}{ccccc}
\hline Laser power & Hatch spacing & Scan velocity & Layer thickness & Scan pattern \\
\hline $285 \mathrm{~W}$ & $0.11 \mathrm{~mm}$ & $960 \mathrm{~mm} / \mathrm{s}$ & $0.04 \mathrm{~mm}$ & Striper, $10 \mathrm{~mm}$ wide, $47^{\circ}$ rotation angle \\
\hline
\end{tabular}

Table 3 Set heat treatment conditions for this study

\begin{tabular}{ccc}
\hline & For tensile test & For microstructure analysis \\
\hline Hybrid 18Ni300-17-4 PH & HT0, HT1, HT2, HT3 & HT0, HT1, HT2, HT3 \\
\hline Stand-alone 18Ni300 & HT0, HT1, HT2, HT3 & Not applicable \\
\hline Wrought 17-4 PH & HT0, HT1, HT2, HT3 & Not applicable
\end{tabular}

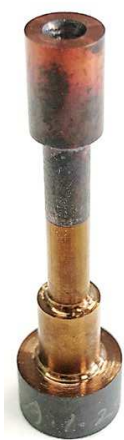

17-4 PH

Substrate

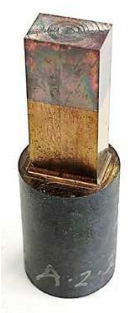

Fig. 4 Pre-machined and heat-treated 18Ni300-17-4 PH samples

\subsection{Characterisation}

\subsubsection{Tensile test}

Standardised tensile tests were performed according to BS EN ISO 6892-1 standard [23] with Instron 1185 tensile testing machines to evaluate the strength of the hybrid-built, stand-alone AM-built and wrought samples. All twelve tensile test specimens were produced by CNC turning, with dimensions as specified in the standard. The four hybrid-built samples were machined with the bonded interface positioned at the middle of the specimen (Fig. 5).

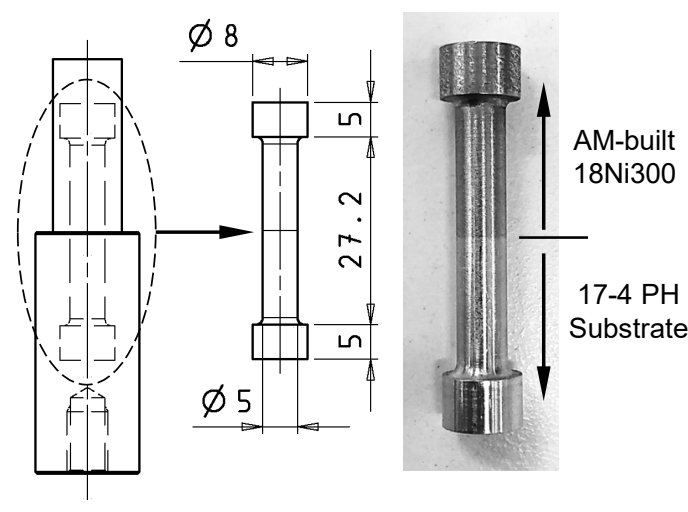

Fig. 5 Hybrid-built tensile test specimen

All tests were executed at room temperature until failure occurred. The parameters used for the tensile tests were:

- Gauge length: $25 \mathrm{~mm}$

- Gauge diameter: $5 \mathrm{~mm}$

- Testing rate: $0.375 \mathrm{~mm} / \mathrm{min}$

\subsubsection{Microstructure analysis}

The microstructural behaviour at the interface of the hybrid-built steel specimens is of prime interest in this study. Standard optical microscopy (OM), scanning electron microscopy (SEM), and 
energy-dispersive X-ray spectroscopy (EDS) techniques were employed to examine the interface. All four specimens were cast in a phenolic mounting block and then polished, lapped, and etched with $3 \%$ Nital (3\% HNO3-97\% Ethanol) etchant (Fig. $6)$.

Before etching, the relative density or porosity of the specimens, an area of $3.6 \mathrm{~mm}$ x $2.2 \mathrm{~mm}$ with the interface roughly in the middle, was measured by the image processing software ImageJ. Micrographs of the microstructure were obtained with an Olympus BX60M optical microscope and an FEI Quanta scanning electrode microscope. The powder-substrate interface thickness of the hybrid-built non-heat-treated specimen was evaluated using EDS line scanning with the scanning electrode microscope.

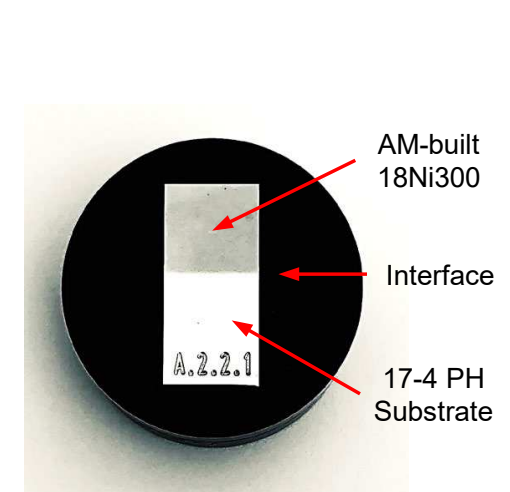

Fig. 6 Mounted specimen for microstructure analysis

\subsubsection{Hardness measurement}

The microhardness line profile (HV0.2) across the interface of the four MA specimens was measured with a Struers DuraScan 50 microhardness tester. The scan length was $1 \mathrm{~mm}$, with the interface being approximately in the middle of the scan. Twenty-one hardness measurements were recorded at $50 \mu \mathrm{m}$ intervals. For discussion purposes, all measured values were converted to the equivalent in Rockwell "C" scale (HRC).

\section{Results and discussions}

The microstructure and mechanical properties of additively manufactured $18 \mathrm{Ni300}$ and conventional wrought 17-4 $\mathrm{PH}$ steel have been well studied and documented in the past two decades. Therefore, the following discussions are focused primarily on the interface region between the powder and substrate materials.

\subsection{Microstructure of the 18Ni300-17-4 PH interface}

\subsubsection{Microstructural observation}

OM and SEM micrographs of the as-built and heat-treated specimens are presented in Figures 7 and 8, respectively. No visible cracks or defects were detected, and the calculated relative density through porosity measurement was 0.999 or $99.9 \%$. Hence, it is fair to consider the four hybridbuilt samples as fully dense. Figure 7a depicts the OM micrographs of the two materials, which correspond to the AM-build direction: AM-deposited $18 \mathrm{Ni} 300$ at the top, 17-4 PH substrate at the bottom. It also shows a region (bound by the two 
red lines) where the transition of the substrate to powder material took place. As evaluated from the EDS line scan (Fig. 9), the thickness of this region in which the transfer of the four major alloying elements, $\mathrm{Cr}, \mathrm{Ni}$, Co and Mo, occurred between the powder and substrate material was approximately $280 \mu \mathrm{m}$.

As shown in Figures 7a, 8a, 8d and 8g, the morphology of the AM-deposited side corresponded with observations reported in past studies on additively manufactured 18Ni300 steel. In Figure 7a, prominent fish-scale morphology of overlapping melt pools was identified at the AMdeposited side of the as-built specimen, typical of LPBF fabricated maraging 300 steel [16]. By contrast, the fish-scale pattern disappeared entirely in the HT1 or solution-treated specimen (Fig. 8a). Instead, the cell-type structure was replaced by a homogenised large lath martensite microstructure, a similar observation reported by Song et al. [24]. In comparison, while still present, the fishscale morphology was barely visible in the direct HT2 and HT3 age-treated specimens (Fig. 8d and $8 \mathrm{~g})$. Moreover, a smaller lath-like structure and small intermetallic precipitates were noticed in these two specimens (Fig. 8e and 8h), bearing a close resemblance to those found on a specimen age-treated with $450{ }^{\circ} \mathrm{C}$ for $6 \mathrm{~h}$ without solution annealing [25].

By definition, the interface region is where fusion bonding of $18 \mathrm{Ni} 300$ powder and wrought
17-4 PH substrate took place. The morphology in this narrow region, as expected, was a blend of the AM-deposited $18 \mathrm{Ni} 300$ and wrought 17-4 PH resulting from the interaction of the laser with the powder and substrate materials. As seen in Figure $7 \mathrm{a}$, the fish-scale morphology of the $18 \mathrm{Ni} 300$ in the upper region was less distinct, gradually becoming less noticeable towards the 17-4 PH substrate side, and eventually disappeared beyond the middle of the region.

A subtle trace of the $18 \mathrm{Ni} 300$ melt pool boundaries was still visible at the upper interface boundary in the as-built and age-hardened specimens (Fig. 7a, 8d and 8g). High magnification $\mathrm{OM}$ images revealed that the original fish-scale morphology became fuzzy (Fig. 7b, 8e and $8 \mathrm{~h})$. Around the middle section of the interface, the microstructure of both $18 \mathrm{Ni} 300$ and 17-4 PH can be seen. In the as-built specimen, a mixture of AM-built $18 \mathrm{Ni} 300$ columnar dendritic and fine submicron equiaxed cells together with wrought solution-treated 17-4 PH structure was detected (Fig. 7c and 7d). Similarly, wellblended microstructures of heat-treated AM-built $18 \mathrm{Ni} 300$ and 17-4 $\mathrm{PH}$ were also found in high magnification SEM micrographs (Fig. 8c, 8f and $8 \mathrm{i})$. This homogenous mixing characteristic of the two materials is further discussed in the following sub-section. 

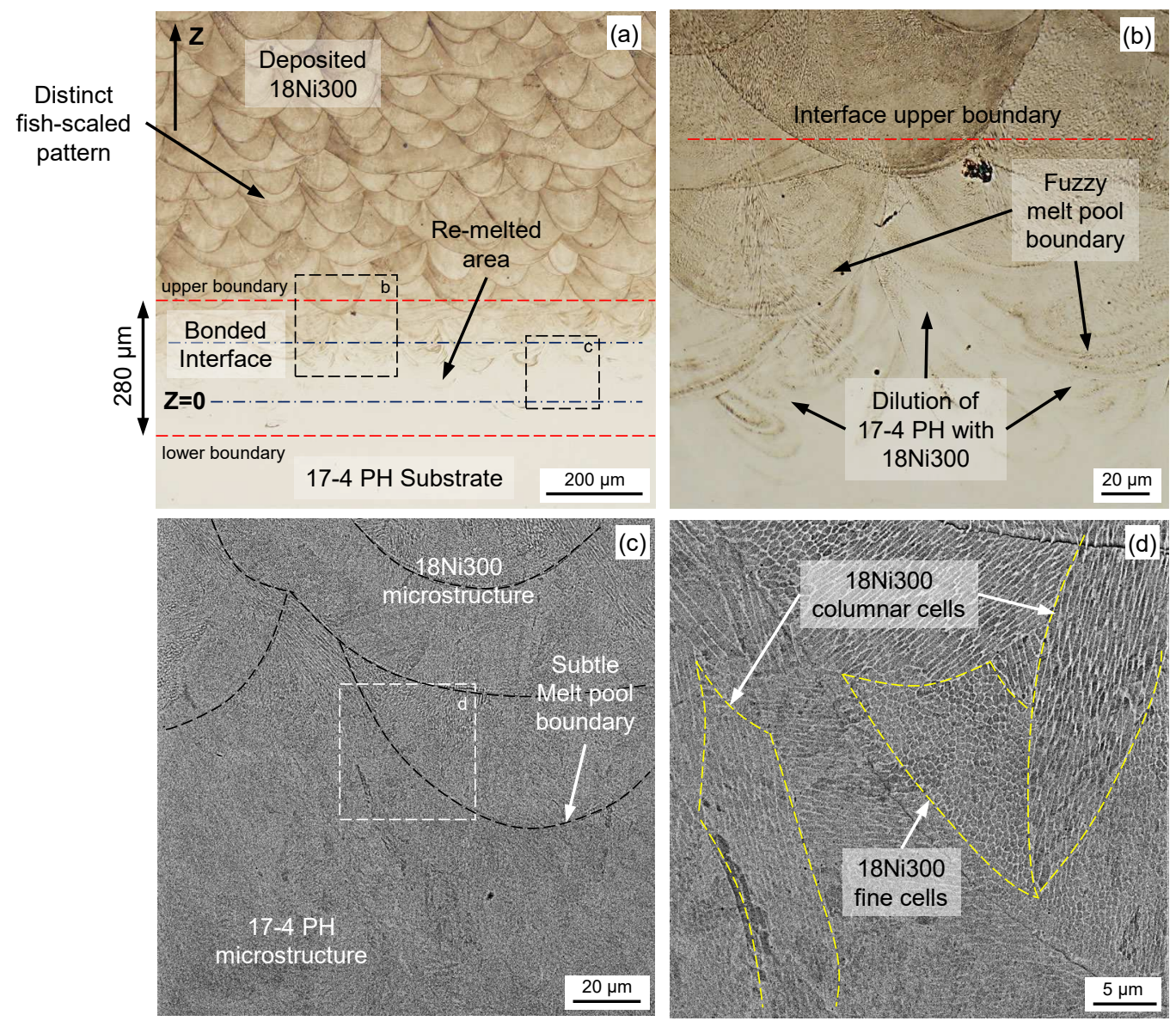

Fig. 7 OM and SEM micrographs of the as-built 18Ni300-17-4 PH specimen

\subsubsection{Characteristic of the bonded interface}

At the start of the AM-build process $(\mathrm{z}=0)$, the partial melting of the 17-4 PH substrate and mixing its alloying elements with the melted $18 \mathrm{Ni} 300$ powder created a dilution effect. Hence, the chemical composition of the melt pool consisted of a mixture of both materials. Dilution of alloying elements has also been reported in hybrid-built 18Ni300-CMnAlNb [26] and 18Ni300-H13 [9] steel parts. EDS line scan performed in this study revealed a homogenous mixing or dilution of the 18Ni300 and 17-4 PH material.

In Figure 9, the rates of change of the four alloying elements were slightly faster during the first quarter of the interface region before they became steady towards the other end, indicating that the dilution of $17-4 \mathrm{PH}$ with $18 \mathrm{Ni} 300$ happened quickly during the start of the AM-build. It is believed to be the result of the fusion process designed for this study. The AM-build process was set to have the first three layers $(120 \mu \mathrm{m})$ of $18 \mathrm{Ni} 300$ powder scanned twice or re-melted. 

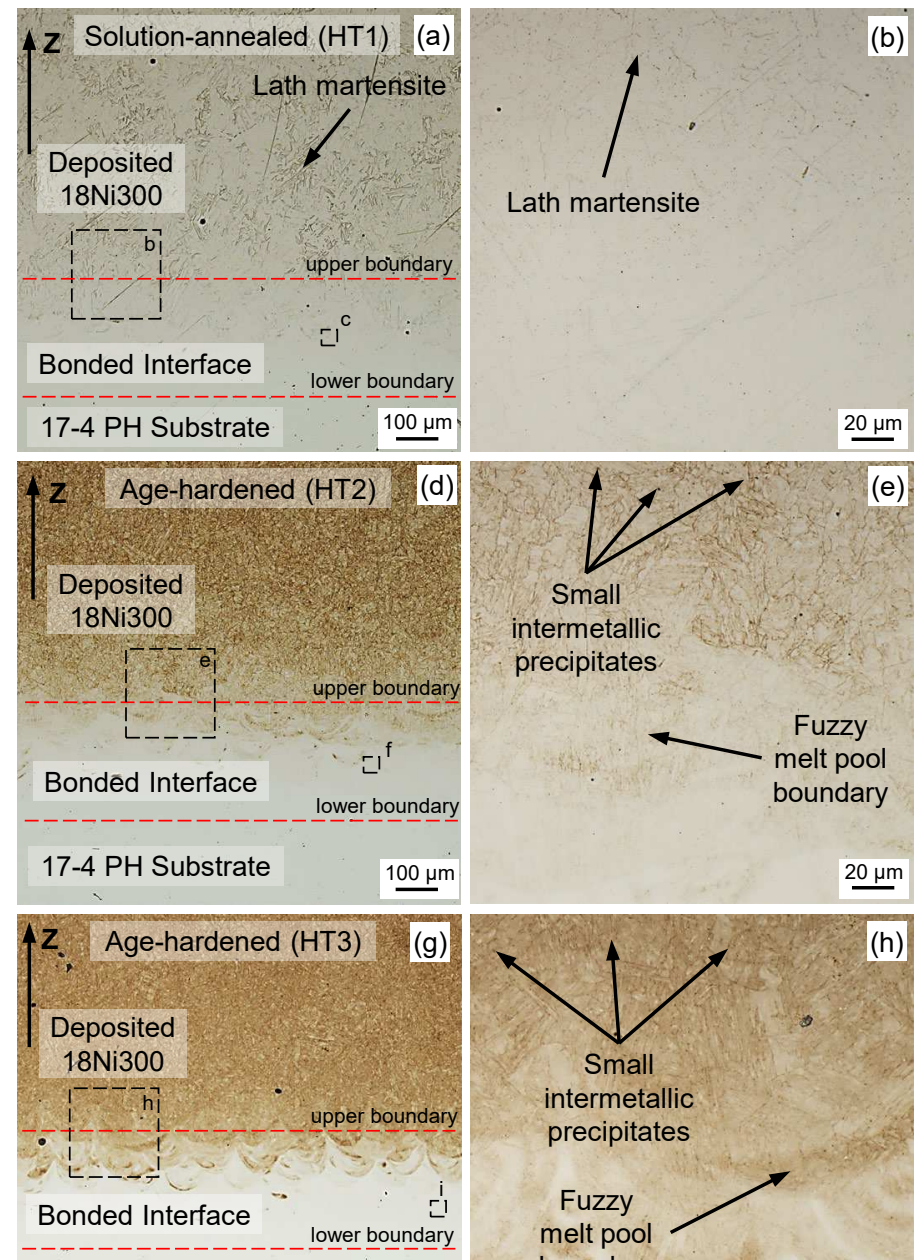

17-4 PH Substrate

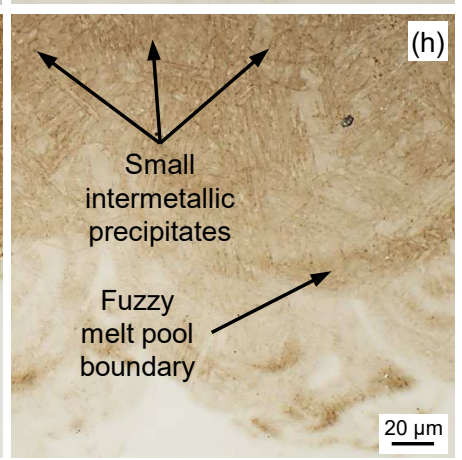

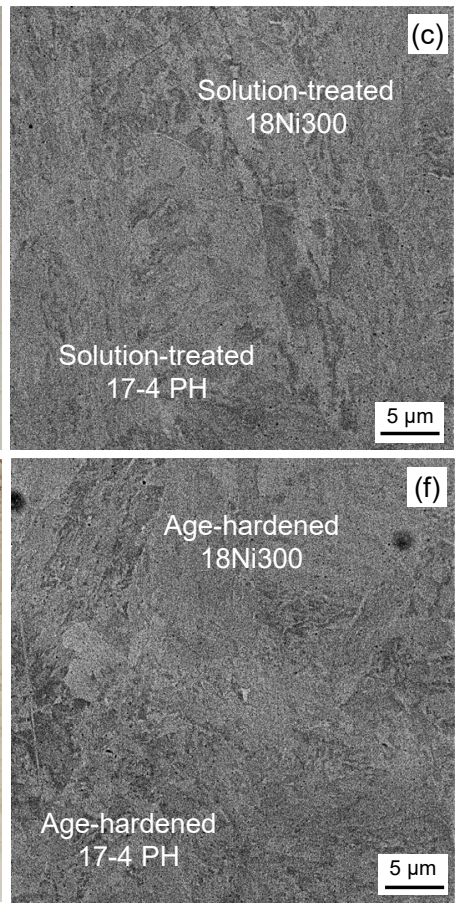

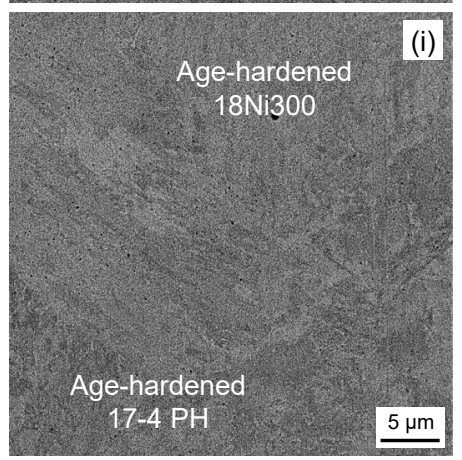

Fig. 8 OM and SEM micrographs of the heat-treated18Ni300-17-4 PH specimens: (a-c) solution annealed with HT1, (d-f) age-hardened with HT2, (g-i) age-hardened with HT3

The re-melting process allowed the alloying elements of the $18 \mathrm{Ni300}$ to penetrate below the substrate top surface twice, facilitating homogenous mixing across the initial $120 \mu \mathrm{m}$ thickness. As the build carried on, the transfer of the alloying elements happened more gradually. Overall, the dilution formed a solid solution rich in alloying elements from the $18 \mathrm{Ni} 300(\mathrm{Ni}, \mathrm{Co}$ and $\mathrm{Mo}$ ) and 17-4 PH (Cr). Consequently, a higher strength interface bond can be expected from this solid solution strengthening mechanism [27]. The effect of this interfacial microstructural change on the mechanical properties of the hybrid-built samples is discussed in the next section. 


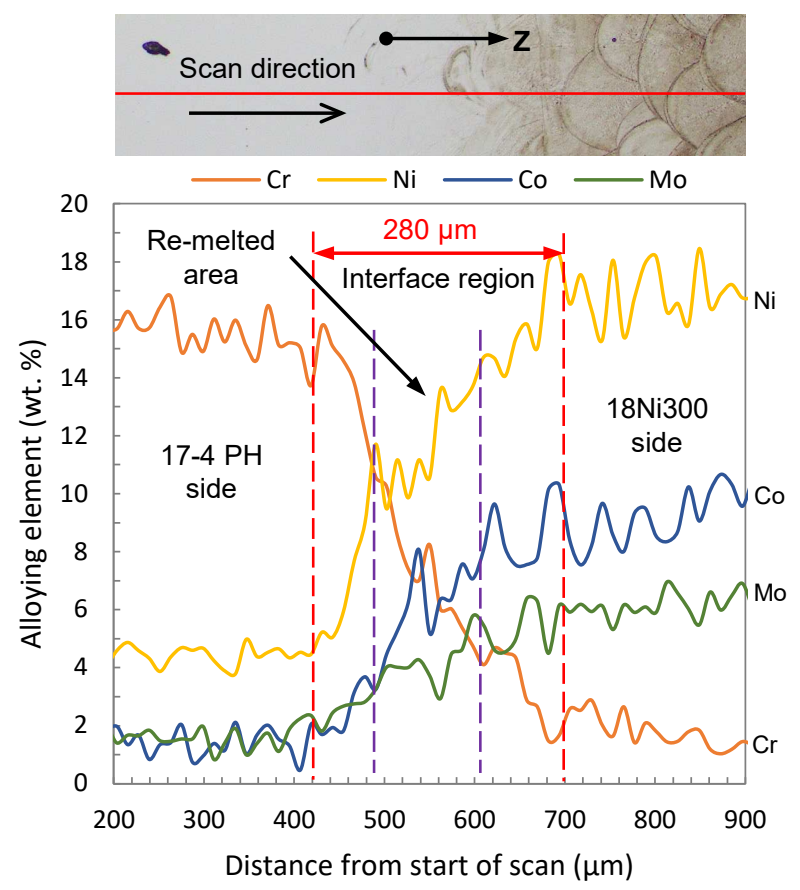

Fig. 9 EDS line scan across the interface of the as-built 18Ni300-17-4PH specimen

\subsection{Mechanical properties}

In the die and mould manufacturing industry, tensile strength, ductility and hardness are considered the three key mechanical properties of tool steels for fabricating strong and durable mould components. Hence, these three key properties of the hybrid-built $18 \mathrm{Ni} 300-17-4 \mathrm{PH}$ parts are discussed in the following subsections to establish the applicability of the hybrid-build concept.

\subsubsection{Hardness}

The results of the microhardness line profile measurements of the four hybrid-built samples are shown in Figure 10. The interface boundaries established from the EDS line scan and the remelting area are also shown for reference. Overall, the effect of different heat treatment conditions on the hardness of the two materials was as expected; hardness was lower with solution-annealing but was higher with age-hardening. The same hardness change pattern was reported in LPBF built maraging 300 steel using the same heat treatment methodology [16].

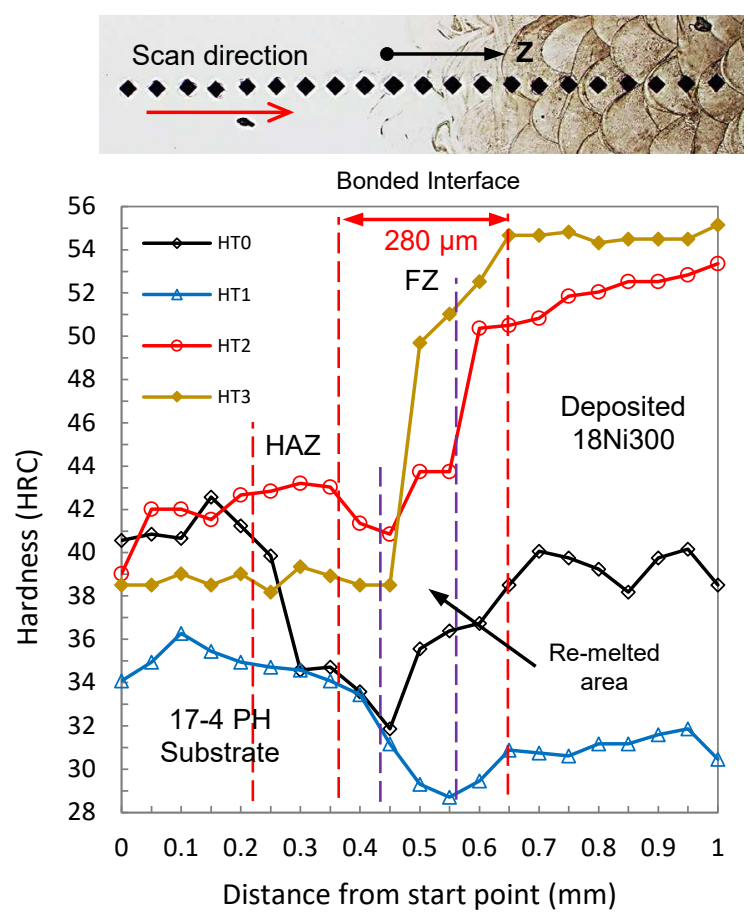

Fig. 10 Microhardness profiles of the hybrid-built samples with different heat treatment conditions

On the AM-deposited $18 \mathrm{Ni300}$ side, the hardness value obtained on the as-built or HT0 sample was about 39 HRC. In comparison, the values on the samples heat-treated with HT1, HT2 and HT3 were about 31,53 and $55 \mathrm{HRC}$, respectively. It can be seen that the hardness dropped by 8 HRC 
hardness points or about $20 \%$ through HT1 treatment. This widely documented softening was the result of the homogenised microstructural change in the material after the solution treatment (ST) process. It was also noticed that further softening could occur with a higher set ST temperature.

In this study, the ST condition was set at 940 ${ }^{\circ} \mathrm{C} / 2 \mathrm{~h}$, the latest recommendation by the powder manufacturer. In comparison, Song et al. [24] used a lower setting of $840{ }^{\circ} \mathrm{C}$ for the same duration and reported a 6 HRC hardness point drop. The extra softening obtained in this study could be beneficial to pre-hardening machining operations. In contrast to solution-annealing, the two age-hardened samples exhibited a relatively big jump in hardness, 14 HRC points or $36 \%$ with HT2 and 16 HRC points or $41 \%$ with HT3. It is worth noting that an additional five hours for HT3 over HT2 resulted only in an additional $5 \%$ gain in hardness. This shorter duration makes the HT2 or $490{ }^{\circ} \mathrm{C} / 1 \mathrm{~h}$ age-hardening treatment a preferable method for injection mould application.

On the 17-4 PH substrate side, although the material followed the same pattern of hardness change from treatment HT1 to HT3, the recorded hardness on the HT3 sample was lower than that of the as-supplied one. A possible explanation would be the incompatibility of the heat treatment setting used on the 17-4 $\mathrm{PH}$ material, as the heat-treatment conditions used in this study were primarily designed for $18 \mathrm{Ni} 300$ steel. According to a previous study [28], a relatively high hardness of about 49 HRC was recorded with a combined solution-age treatment condition set at $1040{ }^{\circ} \mathrm{C} / 0.5 \mathrm{~h}$ followed by $510{ }^{\circ} \mathrm{C} / 1 \mathrm{~h}$. Nevertheless, the 43 HRC hardness obtained on the substrate side of the HT2 sample in this study would still be suitable for mould application.

Around the interface, the hardness profile of the as-built sample followed a down-up pattern across the region from the substrate to the AMdeposited side. The hardness value dropped from about 41 HRC starting at about $1.5 \mathrm{~mm}$ from the interface to $32 \mathrm{HRC}$ inside the region. It then climbed back up to about 39 HRC towards the $18 \mathrm{Ni} 300$ side of the interface before levelling off. The softening behaviour on the 17-4 PH side of the interface was due to the local tempering of the 17-4 PH material. The interface region and its substrate neighbour can be considered equivalent to fusion zone (FZ) and heat-affected zones (HAZ) in the case of conventional laser welding. As the fusion started in the build process, the temperature in the HAZ was high enough to trigger coarsening and dissolution of precipitates of the 17-4 PH [29]. However, the intermetallic precipitates were evenly dispersed with ageing treatments, resulting in a more uniform microhardness profile, as seen in Figure 10. The steady climb of hardness within the fusion zone is evidence of the solid solution strengthening effect 
created by the dilution of $18 \mathrm{Ni} 300$ with $17-4 \mathrm{PH}$, as discussed in Section 4.1.2.

\subsubsection{Fracture behaviour}

All 12 specimens, four of hybrid-built $18 \mathrm{Ni300}$ 17-4 PH, four of stand-alone AM-built 18Ni300, and four of wrought 17-4 PH, were pulled to rupture under uniaxial tensile tests. The fracture behaviour of the hybrid-built samples is of particular interest in this study. Two possible scenarios were anticipated: rupture occurring at the bonded interface or on the side of the material with the lower mechanical strength. Rupture away from the interface would indicate a strong bonding.

Figure 11 shows the photos of the four ruptured hybrid-built specimens, illustrating the rupture points relative to the interface line. As can be seen from the photos, the rupture point occurred about $8 \mathrm{~mm}$ from the interface line on either the AM-built side for the as-built and solutionannealed specimens or the substrate side for the two age-hardened three specimens. No fracture occurred at the interface line, confirming a robust bonding between the powder and substrate material. The intact of the fusion joints is further proof of the solid solution strengthening effect on the interface, as discussed in Section 4.1.2. Furthermore, the necking shape at the rupture points resembled ductile failure, indicating that all samples were non-brittle. These results would provide confidence in using this hybrid-build hybrid-steel technique to manufacture high-performance parts for different applications.

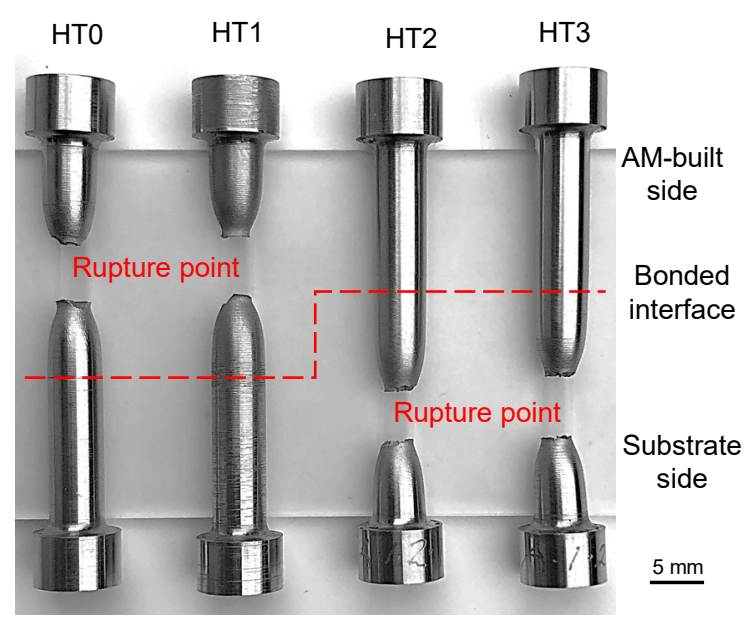

Fig. 11 Hybrid-built 18Ni300-17-4 PH ruptured specimens

\subsubsection{Mechanical strength}

The recorded values of the $0.2 \%$ proof or yield strength (YS), ultimate tensile strength (UTS) and elongation at fracture $(\mathrm{EF})$ were listed in Table 4 . The results for the hybrid-built samples were depicted graphically in Figure 12. For discussion purposes, the strength and ductility of the three groups of samples under the four different heat treatment conditions were shown in Figures $13 \mathrm{a}$ and $\mathrm{b}$.

Among the four hybrid-built samples, the one with the HT2 treatment exhibited the highest YS, UTS and EF of $1220 \mathrm{MPa}, 1329 \mathrm{MPa}$ and $17.4 \%$, respectively. The second highest strength was recorded on the as-built or HT0 sample (UTS $=1200 \mathrm{MPa})$, followed by HT3 (UTS $=1159$ 
$15^{5}$

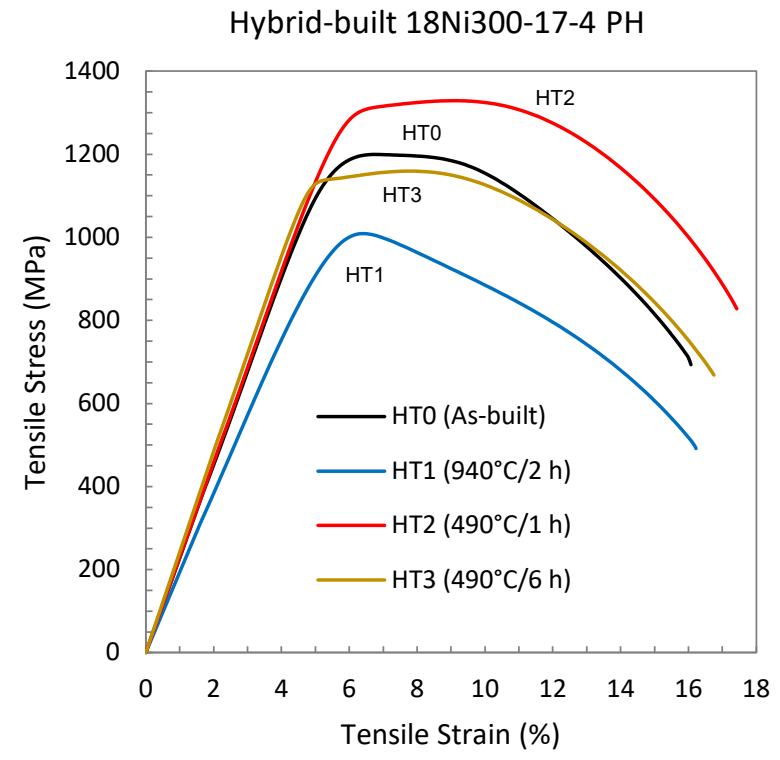

Fig. 12 Tensile stress-strain curves of the hybrid-built specimens with different heat treatments

$\mathrm{MPa})$ and HT1 (UTS = $1009 \mathrm{MPa})$. Compared with the as-built sample, an increase of about $10 \%$ on average in strength was noticed. The strengthening effect on $18 \mathrm{Ni300}$ and 17-4 PH steel resulting from ageing treatment was well documented $[12$, 19]. As expected, the solution-annealing treatment reduced the strength of the HT1 sample substantially, from 1200 to $1009 \mathrm{MPa}$, or about $16 \%$. Overall, the ductility of these four samples could be considered high, with EF values ranging from 16 to $17.5 \%$. Long necking, or elongation from UTS to failure, of about $10 \%$ on the four samples is also proof of high ductility. These results were comparable to the findings reported in a recent hybrid-steel study [26]. When comparing the HT0 with the HT3 sample, the 6-hour ageing treatment had no strengthening effect on the HT3 sample as a whole part. Instead, it lowered its strength by about $4 \%$ and increased its ductility by about the same amount.

In order to better understand the mechanical behaviours of these hybrid-steel parts, a comparison between the hybrid-built, stand-alone AMbuilt $18 \mathrm{Ni} 300$ and wrought $17-4 \mathrm{PH}$ samples is needed. In Figure 13a, it can be seen that the difference in UTS between $18 \mathrm{Ni300}$ and 17-4 PH as a stand-alone material was comparatively large when subjected to the HT2 and HT3 ageing treatments. The same but opposite trend was also noticed in the ductility comparison (Fig. 13b). The stand-alone HT2 and HT3 treated 18Ni300 samples had the two highest strengths $($ UTS $=$ 1847 and $1966 \mathrm{MPa}$ ) but the two lowest ductilities $(\mathrm{EF}=12.6$ and $11.4 \%)$. It would explain why tensile failure with ductile necking occurred on the 17-4 PH substrate side or the weaker side of the hybrid-built HT2 and HT3 samples (Fig. 11). Conversely, under the conditions of HT0 and HT1, stand-alone AM-built 18Ni300 samples were not as strong and as ductile as the 17-4 PH counterparts. Consequently, tensile failure occurred on the weaker side, the AM-built $18 \mathrm{Ni} 300$ side of these two hybrid-built samples (Fig. 11). From these observations and comparisons, the most suitable condition to acquire a balanced strengthductility property for hybrid-built $18 \mathrm{Ni300-17-4}$ PH parts as a whole would be to use the post-build HT2 ageing treatment. 
Table 4 Comparison of mechanical strength

\begin{tabular}{cccc}
\hline Sample & YS (MPa) & UTS (MPa) & EF (\%) \\
\hline Hybrid 18Ni300-17-4 PH (HT0) & 1130 & 1200 & 16.1 \\
\hline Hybrid 18Ni300-17-4 PH (HT1) & 930 & 1009 & 16.3 \\
\hline Hybrid 18Ni300-17-4 PH (HT2) & 1220 & 1329 & 17.4 \\
\hline Hybrid 18Ni300-17-4 PH (HT3) & 1130 & 1159 & 16.8 \\
\hline Stand-alone 18Ni300 (HT0) & 1040 & 1093 & 13.2 \\
\hline Stand-alone 18Ni300 (HT0) & 890 & 996 & 16.1 \\
\hline Stand-alone 18Ni300 (HT0) & 1770 & 1847 & 12.6 \\
\hline Stand-alone 18Ni300 (HT0) & 1940 & 1966 & 11.4 \\
\hline Wrought 17-4 PH (HT0) & 1110 & 1233 & 16.7 \\
\hline Wrought 17-4 PH (HT0) & 940 & 1098 & 17.1 \\
\hline Wrought 17-4 PH (HT0) & 1310 & 1372 & 18.7 \\
\hline Wrought 17-4 PH (HT0) & 1240 & 1285 & 18.8 \\
\hline
\end{tabular}
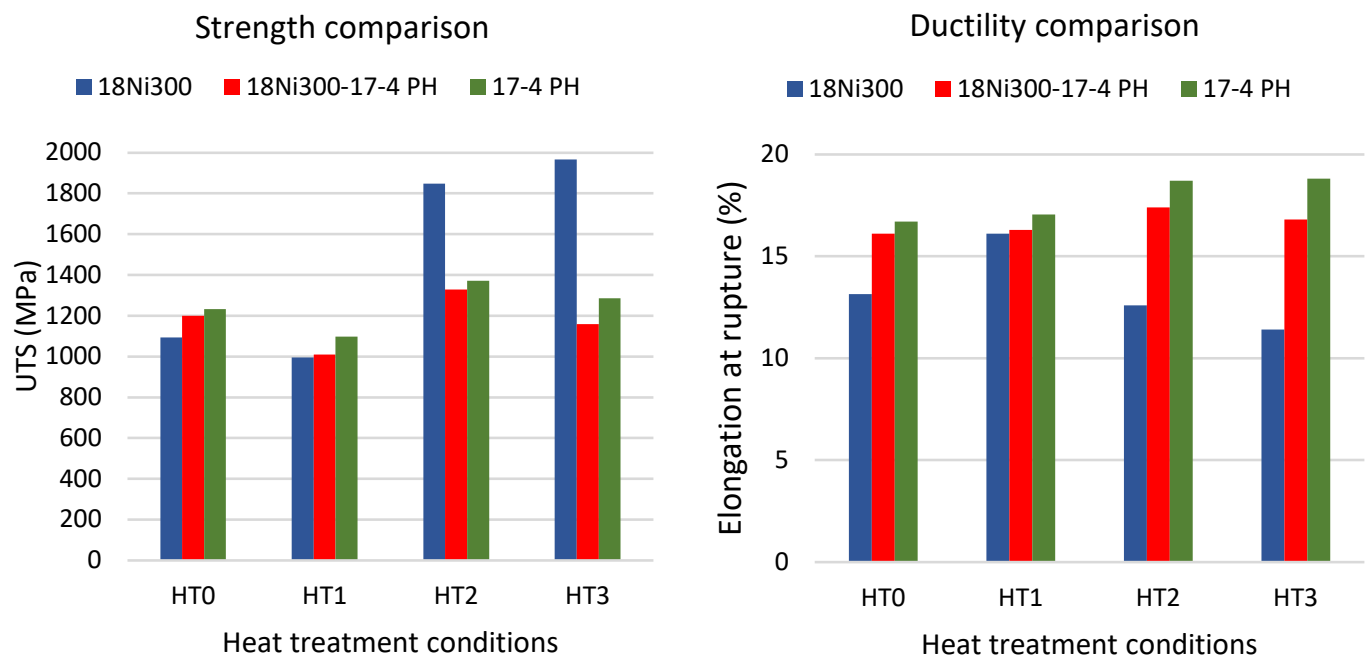

Fig. 13 Bar charts comparing the difference between hybrid-built and stand-alone samples under the four different heat treatment conditions, a) in strength, b) in ductility

In summary, microstructure analysis and the hybrid-build technique. Furthermore, agemechanical testing revealed fully dense and hardened hybrid-built $18 \mathrm{Ni300-17-4} \mathrm{PH}$ steel strong interface bonds between the powder and substrate materials, confirming the success of parts possessed high mechanical strength, high hardness and high ductility. The best combination of strength (1329 MPa), hardness (43/53 HRC) 
and ductility (17.4\%) was attained on the sample with the post-build direct $490{ }^{\circ} \mathrm{C} / 1 \mathrm{~h}$ ageing treatment.

\section{Potential application}

The findings from this study open up opportunities for mould designers and mould makers to combine the new metal AM technology with wellestablished conventional practice. Figure 14 shows an example of how this hybrid-build concept can produce a durable mould insert with high cooling efficiency.

The core, as an insert, is part of the mould that produces a drink bottle screw cap. This design shows how cooling water can get up to the top to cool around the thread via conformal cooling channels (CCC). This portion of the core, including the internal product shape, in $18 \mathrm{Ni} 300$ steel, will be additively fabricated on a pre-machined 17$4 \mathrm{PH}$ round blank using the LPBF process. The wrought 17-4 PH portion will form the base of the core insert. The AM-build CCC will link up with the pre-machined cooling holes in the substrate blank to form a complete cooling circuit.

After the LPBF and heat treatment process, the core will be finish-machined to its final shape and details. Future detailed investigation on manufacturing costs and mould performance of this proposed design could prove the cost-effectiveness of this LPBF-machined substrate hybrid AM strategy.

\section{Conclusion}

In this study, hybrid-steel parts were successfully fabricated additively by depositing $18 \mathrm{Ni300}$ steel powder on pre-machined wrought 17-4 PH stainless steel using the LPBF process. Experimental results on mechanical and metallurgical properties of the hybrid-built parts confirmed the practicability of the hybrid-build hybrid-steel manufacturing technique. The key findings from this study can be summarised as follows:

- A bonded interface region of approximately $280 /$ mum in thickness was formed between the powder and substrate steel by the LPBF process.

- OM and SEM micrographs revealed good penetration and dilution of deposited powder with the substrate, proving a high integrity fusion bond.

- Parts fabricated using the hybrid-build method exhibit strong powder-to-substrate bonding with tensile failure that occurred well away from the interface on the side of the material with the lower strength.

- The most suitable post-build heat treatment to produce hybrid-built parts of high strength, high hardness and high ductility was the direct $490{ }^{\circ} \mathrm{C} / 1 \mathrm{~h}$ method. 
Acknowledgments. The authors wish to thank CAMEX 2018 Limited for providing the machinery and labour to prepare the samples.

\section{Declarations}

- Funding This research study received no funding from any organisation.

\section{- Conflict of interest/Competing interests}

The authors declare that they have no conflict of interest.

- Ethics approval This research study does not involve human participants, and is to be used for non-life science journals, hence ethical approval is not applicable.

- Consent to participate This research study does not involve human participants, and is to be used for non-life science journals, hence consent to participate is not applicable.

- Consent for publication The authors give permission for the publishing of this article.

- Availability of data and materials The authors are happy to make all the raw experimental data available to anyone who requests it.

- Authors' contributions This research will provide a practical solution for combining powder and wrought tool steel for fabricating durable mould insert using the laser powder bed 
fusion process. Simon Chan, as a $\mathrm{PhD}$ student undertook the bulk of the hands-on research part of the project, under the supervision of Olaf Diegel and $\mathrm{Xun} \mathrm{Xu}$, and the paper was collaboratively written by Simon Chan, Olaf Diegel and Xun $\mathrm{Xu}$.

\section{References}

[1] ASTM, ISO (2015) ISO/ASTM 52900:2015(E) Standard Terminology for Additive Manufacturing - General Principles - Terminology. ASTM Stand p 9, URL http://compass.astm.org.ezproxy.lib.vt.edu/ download/ISOASTM52900.8777.pdf

[2] Berger GR, Zorn D, Friesenbichler W, Bevc F, Bodor CJ (2019) Efficient cooling of hot spots in injection molding. A biomimetic cooling channel versus a heat-conductive mold material and a heat conductive plastics. Polym Eng Sci 59(s2):E180-E188, DOI 10. 1002/pen.25024

[3] Abbès B, Abbès F, Abdessalam H, Upganlawar A (2019) Finite element cooling simulations of conformal cooling hybrid injection molding tools manufactured by selective laser melting. Int J Adv Manuf Technol 103(58):2515-2522, DOI https://doi.org/10.1007/ s00170-019-03721-2
[4] Mazur M, Brincat P, Leary M, Brandt M (2017) Numerical and experimental evaluation of a conformally cooled H13 steel injection mould manufactured with selective laser melting. Int J Adv Manuf Technol 93(14):881-900, DOI 10.1007/s00170-017-0426-7

[5] Chan YL, Diegel O, Xu X (2020) A machined substrate hybrid additive manufacturing strategy for injection moulding inserts. Int J Adv Manuf Technol DOI 10.1007/ s00170-020-06366-8

[6] Chan YL, Diegel O, Xu X (2021) Evaluation of bonding integrity of hybrid-built AlSi10Mg-aluminium alloys parts using the powder bed fusion process. Mater Today Proc 46:1277-1282, DOI 10.1016/j.matpr.2021.02. 126, URL https://doi.org/10.1016/j.matpr. 2021.02.126

[7] Kazmer DO (2016) Injection Mold Design Engineering, 2nd edn. Hanser Publishers, Munich, DOI 10.3139/9783446434196.fm

[8] Cyr E, Asgari H, Shamsdini S, Purdy M, Hosseinkhani K, Mohammadi M (2018) Fracture behaviour of additively manufactured MS1H13 hybrid hard steels. Mater Lett 212:174177, DOI 10.1016/j.matlet.2017.10.097, URL https://doi.org/10.1016/j.matlet.2017.10.097

[9] Azizi H, Ghiaasiaan R, Prager R, Ghoncheh MH, Samk KA, Lausic A, Byleveld W, Phillion AB (2019) Metallurgical and mechanical assessment of hybrid 
additively-manufactured maraging tool steels via selective laser melting. Addit Manuf 27(October 2018):389-397, DOI 10.1016/j.addma.2019.03.025, URL https: //doi.org/10.1016/j.addma.2019.03.025

[10] Santos LM, de Jesus J, Ferreira JM, Costa JD, Capela C (2018) Fracture toughness of hybrid components with Selective Laser Melting 18Ni300 steel parts. Appl Sci 8(10), DOI 10.3390/app8101879

[11] Böhler (2005) Data Sheet Maraging High Strength Steel. Tech. rep.

[12] Yasa E, Kempen K, Kruth JP, Thijs L, Van Humbeeck J (2010) MICROSTRUCTURE AND MECHANICAL PROPERTIES OF MARAGING STEEL 300 AFTER SELECTIVE LASER MELTING. Solid Free Fabr Symp Proc pp 383-396

[13] Bhardwaj T, Shukla M (2018) Effect of laser scanning strategies on texture, physical and mechanical properties of laser sintered maraging steel. Mater Sci Eng A 734(June):102-109, DOI 10.1016/j.msea. 2018.07.089, URL https://doi.org/10.1016/j. msea.2018.07.089

[14] Shamsdini SAR, Shakerin S, Hadadzadeh A, Amirkhiz BS, Mohammadi M (2020) A trade-off between powder layer thickness and mechanical properties in additively manufactured maraging steels. Mater Sci Eng A
776(December 2019):139041, DOI 10.1016/j. msea.2020.139041, URL https://doi.org/10. 1016/j.msea.2020.139041

[15] Carson C (2014) Heat Treating of Maraging Steels. In: ASM Handbook, Vol. 4D Heat Treat. Irons Steels, vol 4D, ASM International, pp 468-480, DOI 10.31399/asm.hb. v04d.a0005948

[16] Tan C, Zhou K, Ma W, Zhang P, Liu M, Kuang T (2017) Microstructural evolution, nanoprecipitation behavior and mechanical properties of selective laser melted high-performance grade 300 maraging steel. Mater Des 134:23-34, DOI 10.1016/j.matdes. 2017.08.026, URL https://doi.org/10.1016/j. matdes.2017.08.026

[17] Bai Y, Zhao C, Yang J, Hong R, Weng C, Wang H (2021) Microstructure and machinability of selective laser melted highstrength maraging steel with heat treatment. J Mater Process Technol 288(September 2020):116906, DOI 10.1016/j.jmatprotec. 2020.116906, URL https://doi.org/10.1016/j. jmatprotec.2020.116906

[18] Böhler (2003) Data sheet 17-4 PH Stainless Steel. Tech. rep.

[19] Yoo WD, Lee JH, Youn KT, Rhyim YM (2006) Study on the microstructure and mechanical properties of 17-4 $\mathrm{PH}$ stainless steel depending on heat treatment and aging time. Solid State Phenom 118:15-20, DOI 10. 
[20] Hsiao CN, Chiou CS, Yang JR (2002) Aging reactions in a 17-4 PH stainless steel. Mater Chem Phys 74(2):134-142, DOI 10.1016/ S0254-0584(01)00460-6

[21] Murayama M, Katayama Y, Hono K (1999) Microstructural evolution in a 17-4 PH stainless steel after aging at $400{ }^{\circ} \mathrm{C}$. Metall Mater Trans A Phys Metall Mater Sci 30(2):345353, DOI 10.1007/s11661-999-0323-2

[22] EOS (2020) Inspection Certificate, EOS Maraging Steel MS1. Tech. Rep. 1

[23] CEN, BSI (2019) BS EN ISO 6892-1: 2019 Metallic materials - Tensile testing Part 1: Methods of test at room temperature. Bristish Stand

[24] Song J, Tang Q, Feng Q, Ma S, Setchi R, Liu Y, Han Q, Fan X, Zhang M (2019) Effect of heat treatment on microstructure and mechanical behaviours of $18 \mathrm{Ni}-300$ maraging steel manufactured by selective laser melting. Opt Laser Technol 120(June):105725, DOI 10.1016/j.optlastec.2019.105725, URL https: //doi.org/10.1016/j.optlastec.2019.105725

[25] Kim D, Kim T, Ha K, Oak JJ, Jeon JB, Park Y, Lee W (2020) Effect of heat treatment condition on microstructural and mechanical anisotropies of selective laser melted maraging 18Ni-300 steel. Metals (Basel) 10(3), DOI $10.3390 / \operatorname{met} 10030410$
[26] Kučerová L, Zetková I, Jeníček Š, Burdová K (2020) Hybrid parts produced by deposition of $18 \mathrm{Ni} 300$ maraging steel via selective laser melting on forged and heat treated advanced high strength steel. Addit Manuf 32(November 2019), DOI 10.1016/j.addma.2020.101108

[27] Shakerin S, Hadadzadeh A, Amirkhiz BS, Shamsdini S, Li J, Mohammadi M (2019) Additive manufacturing of maraging steel-H13 bimetals using laser powder bed fusion technique. Addit Manuf 29(January):100797, DOI 10.1016/j.addma.2019.100797, URL https: //doi.org/10.1016/j.addma.2019.100797

[28] Viswanathan UK, Banerjee S, Krishnan R (1988) Effects of aging on the microstructure of 17-4 PH stainless steel. Mater Sci Eng 104(C):181-189, DOI 10.1016/0025-5416(88) 90420-X

[29] Bahrami Balajaddeh M, Naffakh-Moosavy H (2019) Pulsed Nd:YAG laser welding of 17-4 PH stainless steel: Microstructure, mechanical properties, and weldability investigation. Opt Laser Technol 119(April), DOI 10.1016/ j.optlastec.2019.105651 